\title{
MECHANICAL SIMULATIONS OF SANDIA II TESTS OECD ISP 48 BENCHMARK
}

\author{
Sh. Ghavamian \\ EDF R\&D, 1 avenue du Général de \\ Gaulle - 92141 Clamart, France
}

\author{
A. Courtois, J.L. Valfort \\ EDF SEPTEN, 12-14, avenue Dutriévoz - \\ 69628 Villeurbanne Cedex, France
}

\begin{abstract}
This paper illustrates the work carried out by EDF within the framework of ISP48 post-test analysis of NUPEC/NRCN 1:4-scale model of a prestressed pressure containment vessel of a nuclear power plant. EDF as a participant of the International Standard Problem n ${ }^{\circ} 48$ has performed several simulations to determine the ultimate response of the scale model. To determine the most influent parameter in such an analysis several studies were carried out. The mesh was built using a parametric tool to measure the influence of discretization on results. Different material laws of concrete were also used. The purpose of this paper is to illustrate the ultimate behaviour of SANDIA II model obtained by Code_Aster ${ }^{\circledR}$ with comparison to tests records, and also to share the lessons learned from the parametric computations and precautions that must be taken.
\end{abstract}

Keywords: containment vessels, concrete, failure, experiment, benchmark, FE analysis

\section{INTRODUCTION}

The safety of nuclear power plants must be guaranteed at any moment. Especially in case of an accident involving the release of toxic substances. The reactor building is designed to prevent the installations from external aggressions, but also provide leakage tightness to avoid toxic gases to reach the environment. At EDF, reactor buildings are regularly monitored through air leak tests. Structural simulations also accompany these tests in order to predict their evolution caused by long term behaviour of the structure (concrete creep and drying) which may affect the transfer properties of pressure containment vessel where leakage tightness is provided by the thickness of concrete (no steel liner). For this purpose several sophisticated simulations techniques have been developed at EDF Research \& Development and implemented in Code_Aster ${ }^{\circledR}$ a general purpose finite element platform. These concern material constitutive models for concrete, reinforcements, and prestressed tendon modelling and resolution algorithms.

Because of the great number of non linearities that could be used within the same simulation these tend to become more and more complex and hard to be validated. This is why experimental validations become essential to qualify our tools and methods. SANDIA II benchmarking appeared to us to be an opportunity to verify the robustness and degree of confidence in our numerical tools and methods. The work carried out in this study was to simulate the ultimate capacity of SANDIA model when it reached its structural capacity and collapsed. Further work is in course to include drying, shrinkage and creep of the structure prior to the final test. To us these are essential to well determine the initial mechanical state of the structure.

\section{METHODOLOGY}

Prior to any modelling of the mock-up several questions needed to be answered in order to establish the appropriate approach. These were: What are the exact aims of the simulations? What are the physics involved, and their importance to reach this goal? What could be the acceptable amount of time and effort for these simulations. 
Our main guidance was to establish the simplest FE modelling to reach the ultimate capacity of the structure, with a reasonable level of agreement in local measures and rupture mechanism and location within the building.

The complexity of such a structure can be appreciated by running through the great number of design layouts, construction and posttest reports, as well as experimental conditions. Considering that the mechanical failure of the building is characterised by the rupture of its tendons leading to the sudden burst of the vessel, not every technical detail of the mock-up needed to be modelled. Referring to previous analyses and those performed by other participants of the SANDIA Pretest program, we made the decision to incorporate the following items within our modelling:

- All concrete parts (basemat, cylindrical wall, dome, additional thickness close to hatches, buttresses), - All tendons individually,

- All reinforcement, inner and outer grids. In both vertical and horizontal directions,

- The entire liner covering the inner surface of the vessel,

- Steel hatches covers.

Most of the simplifications concerned the connectivity conditions between different parts of the model. Liner plates, reinforcement grids as well as tendon cables were considered fully attached to concrete with no additional stiffness, or bond slip possibility. Although necessary for accurate prediction of concrete crack distribution and crack opening, that lead to strain growth in steel reinforcement bars, tendon cables and liner, these are quite complex kinematic modellings that require heavy mesh refinements and special care to avoid the localisation phenomena (Pijaudier-Cabot et al. 1991). Fully detailed modelling also requires a thorough knowledge of on site building conditions and coupled material properties in order to determine the parameter of all corresponding nonlinear material constitutive laws.

In the mock-up, tendon cables were placed in empty ducts. This allowed them to slide as the internal pressure grows during the tests. As a result, prestressing variations along each cable could change from the initial condition to more uniform state. Considering the complications that this would have brought to our modelling, this was possibility was not included in our modelling. This point is later discussed in this paper along with other parametric studies and obtained results.

Because of their great number and potential numerical difficulties that could be encountered during simulations, reinforcement bars were not considered individually. They were represented as equivalent distributed steel densities using shell elements. The steel liner was also treated the same way.

Regarding test conditions it is important to underline time dependent phenomena such as concrete drying, shrinkage, creep and heat variations. It should be noticed that the mock-up was submitted to several loading sequences for almost two years of experimental campaign at SANDIA Laboratories. These could raise the question concerning the exact initial mechanical state of the structure prior to the final test. Direct consequence of this unknown condition is the level of prestressing in each tendon.

Based on these points a 3D FE model of the entire structure was created and fully described later in this paper. The final interrogation concerned mesh discretization. This was left as an unknown parameter to be investigated by performing several mesh sensitivity studies. For this purpose a mesh generation script was also developed.

\section{EXPERIMENTAL DESCRIPTION}

The mock-up was a 1:4 scale model of the prestressed concrete containment vessel (PCCV) of an actual nuclear poser plant in Japan (Figure 1). This is an 1127 MWe Pressurized Water Reactor (PWR) unit, built out of a thin prestressed concrete cylindrical shell with a hemispherical dome and a continuous steel liner anchored to a reinforced concrete basemat. Consistent with the objectives of the sponsoring organizations (NUPEC/NRC), the features and scale of the PCCV model were chosen so that the response of the model would mimic the global behaviour of the prototype and local details. 

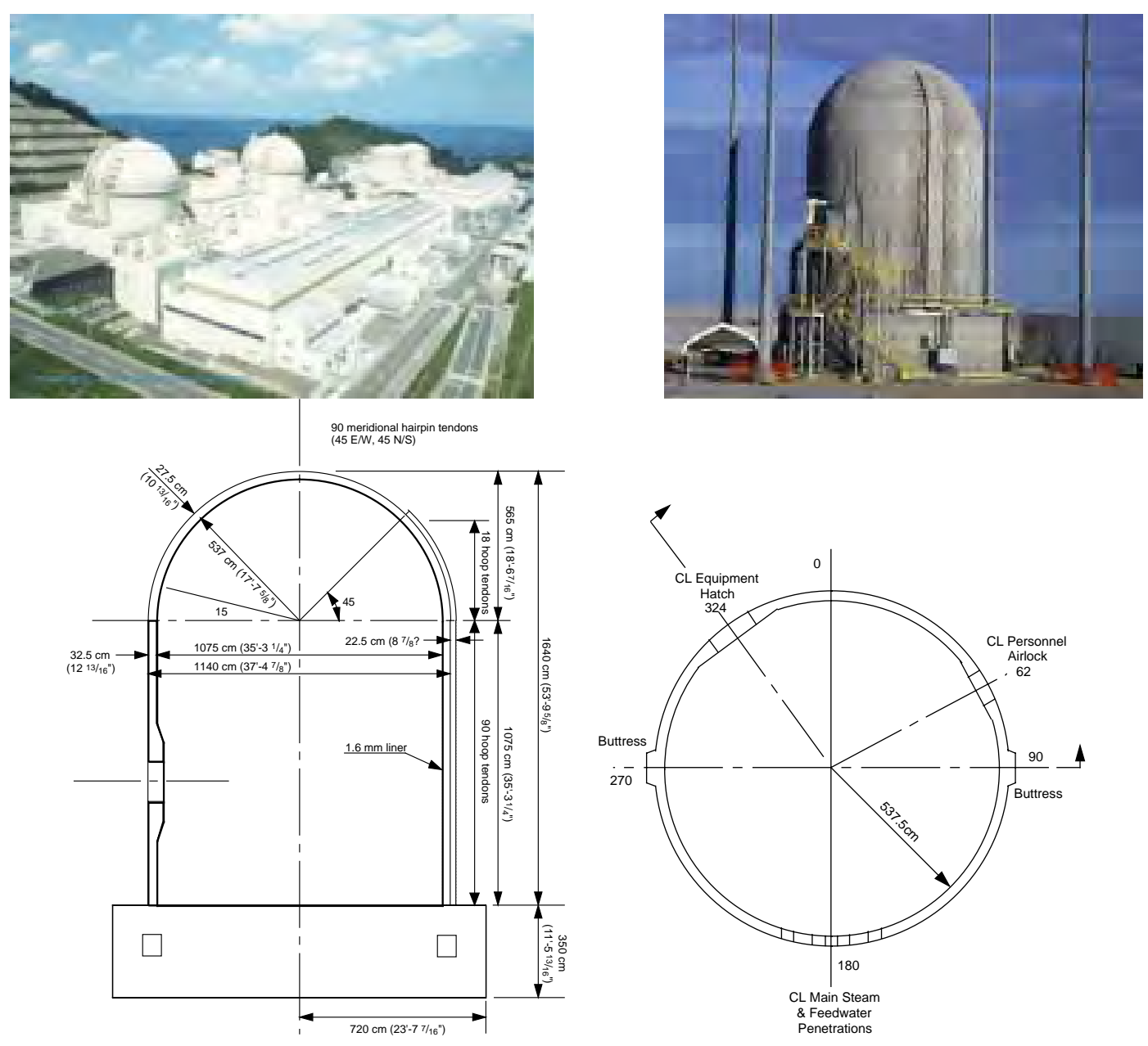

Figure 1. SANDIA II mock-up

(top left: real nuclear power plant, top right: 1:4 scale model, bottom: its geometries)

The experimental campaign was carried out at the Containment Technology Test Facility-West at Sandia National Laboratories, Albuquerque, New Mexico. Construction of the PCCV model started January $3^{\text {rd }}, 1997$ with initial site preparation. Milestones of the program are as follow:

$\begin{array}{lll}\text { 12 February } & 1997 & \text { First Basemat Pour } \\ \text { 19 June } & 1997 & \text { First Liner Panel Installed } \\ \text { 15 April } & 1999 & \text { Final Dome Pour } \\ \text { 12-14 October } & 1999 & \text { Pretest Round Robin Meeting } \\ \text { 8 March to 3rd May } & 2000 & \begin{array}{l}\text { Prestressing } \\ \text { 25 June }\end{array} \\ & 2000 & \text { PCCV Construction Completed } \\ \text { 12-14 September } & 2000 & \text { Structural Integrity and Integrated Leak Rate Test } \\ \text { 27-28 September } & 2000 & \text { Limit State Test } \\ \text { 14 November } & 2002 & \text { Structural Failure Mode Test } \\ \text { 3 }^{\text {rd }} \text { May } & 2002 & \text { PCCV Demolition and Site Restoration Completed }\end{array}$

The purpose of these tests was to evaluate the capacity of the model in terms of air leak tightness and structural stability. These are both necessary to satisfy the function of a pressure containment vessel, which is to prevent toxic substances from passing to the surrounding environment of a nuclear power plant. 


\subsection{PCCV structure}

Geometrical details of the model are presented in Figure 1. The steel liner had a thickness of $1.6 \mathrm{~mm}$ and covered the entire inner surface of the vessel. Vertical and horizontal reinforcement rebars were placed on both inner and outer sides of the wall. 90 vertical and 108 horizontal tendons also covered the entire vessel from basemat to the dome. Two main penetrations were designed for the model (personal airlock and equipment hatch).

\subsection{Material characteristics}

The mock-up was built out of 5 different constituents: concrete, steel liner, steel tendons, steel rebars and steel penetration covers. A great number of material tests were carried out by SNL (Hessheimer et al. 2003). For the purpose of our analysis mean values were considered. Table 1 indicates all these data.

$\begin{array}{lll}\text { Concrete (basemat) } & & \\ \text { Young's modulus } & (\mathrm{MPa}) & 27,000 \\ \text { Poisson ratio } & (.) & 0.21 \\ \text { Density } & \left(\mathrm{kg} / \mathrm{m}^{3}\right) & 2,176 \\ & & \\ \text { Concrete (wall and dome) } & & \\ \text { Young's modulus } & (\mathrm{MPa}) & 27,000 \\ \text { Poisson ratio } & (.) & 0.21 \\ \text { Density } & \left(\mathrm{kg} / \mathrm{m}^{3}\right) & 2,176 \\ \text { Tensile limit stress } & (\mathrm{MPa}) & 3.5-2.3 \\ \text { Compressive limit stress } & (\mathrm{MPa}) & 60.3 \\ & & \\ \text { Steel (liner) } & & \\ \text { Young's modulus } & (\mathrm{MPa}) & 210,000 \\ \text { Poisson ratio } & (.) & 0.3 \\ \text { Density } & \left(\mathrm{kg} / \mathrm{m}^{3}\right) & 7,850 \\ \text { Yielding stress } & (\mathrm{MPa}) & 400 \\ \text { Rupture stress } & (\mathrm{MPa}) & 500 \\ \text { Rupture strain } & (.) & 20 \% \\ & & \end{array}$

\section{Table 1. Material parameters used for FE analyses}

\begin{tabular}{lll} 
Steel (rebars) & & \\
Young's modulus & $(\mathrm{MPa})$ & 185,000 \\
Poisson ratio & $()$. & 0.3 \\
Density & $\left(\mathrm{kg} / \mathrm{m}^{3}\right)$ & 7,850 \\
Yielding stress & $(\mathrm{MPa})$ & 408 \\
Rupture stress & $(\mathrm{MPa})$ & 600 \\
Rupture strain & $()$. & $15 \%$ \\
& & \\
Steel (tendons) & & \\
\hline Young's modulus & $(\mathrm{MPa})$ & 200,000 \\
Poisson ratio & $()$. & 0.3 \\
Density & $\left(\mathrm{kg} / \mathrm{m}^{3}\right)$ & 7,850 \\
Yielding stress & $(\mathrm{MPa})$ & 1,400 \\
Rupture stress & $(\mathrm{MPa})$ & 1,900 \\
Rupture strain & $()$. & $4 \%$ \\
& & \\
Tendons & & \\
Anchorage sit back & $(\mathrm{mm})$ & 5 \\
wobble friction & $\left(\mathrm{m}^{-1}\right)$ & 0.001 \\
Angula friction & $\left(\mathrm{rad}^{-1}\right)$ & 0.21 \\
Vertical prestress & $(\mathrm{N})$ & 424,000 \\
Horizontal prestress & $(\mathrm{N})$ & 304,000
\end{tabular}

\subsection{Loading conditions}

The exact loadings to which the model was submitted are very complex and of different types (temperature, humidity, and mechanics). The extreme levels of temperature in the desert of New Mexico and its daily and seasonal variations can induce significant variations both on humidity content in concrete and thermal strains. These can also greatly affect shrinkage and creep. As a result the level in prestressing applied by tendons could fluctuate. Several tests with different levels of internal pressures have been carried out before the ultimate capacity test simulated in this work. Considering that tendon ducts were not grouted, these could also affect the prestressing distribution along tendons that tend towards more homogeneous state. A part from body weight, prestressing, and internal air pressure, the vessel was almost fully filled up by water during the ultimate test. This was necessary to reach the burst of the structure.

\subsection{Instrumentation and records}

Many different kinds of measures were performed during the tests. These were: load (internal pressure), displacement, rebar strain, concrete strain, concrete crack mapping, liner and liner anchor strain, tendon force, and temperature. Acoustic monitoring was also performed for these tests. Measurements were made at different locations both along height and azimuth of the model. 55 of these records were then selected for the benchmarking purposes. 


\section{ANALYSIS}

\subsection{FE program}

EDF has developed over the last thirteen-years period a finite element platform named Code_Aster ${ }^{\circledR}$ (www.code_aster.org). Widely used for the expertise and maintenance of power plants and electrical networks, this tool covers a wide range of applications: thermal and mechanical analysis - 3D linear or non linear, static or dynamic analysis of pressure vessels - machines - civil engineering and porous media.

In the forecast and the control of the mechanical resistance of civil engineering structures dedicated to electricity production, such as the 58 concrete pressure containment vessels and the 28 cooling towers of nuclear power plants, or the 213 concrete or weight dams, EDF is dominantly preoccupied by their safety. The established layout of Code_Aster ${ }^{\circledR}$ in performing nonlinear simulations of reinforced and pre-stressed concrete structures provides an opportunity to numerically monitor their evolution in time. To evaluate the service life of a concrete structure by anticipating repairs and preventing further damages, the knowledge of the early age and mature behaviour of the concrete in time is essential. That is why Code_Aster ${ }^{\circledR}$ has been endowed with different constitutive laws specific to concrete, and surrounded by simulation methodologies and a great number of analyses and experimental validations. These mainly focus on thermo-hydration and drying, shrinkage, cracking, damage, and creep of concrete, but also the modelling of active and passive reinforcements. In addition to mechanical resistance, other issues need to be addressed. Not only the leakage of pre-stressed reinforced pressure containment vessels of nuclear power plants and their long term strains have to be considered, but also the consequences of severe accidents such as ground motions, loss of primary cooling system and impact of projectiles should be integrated.

\subsection{FE model}

SANDIA II mock-up is a replica of a real reactor building. It includes most of the complexity of a real structure: openings, thickness variations, basemat, dome, buttresses, and a large number of non-uniform layout of prestressing tendons and reinforcement rebars. That is why to describe faithfully its ultimate behaviour it is strongly recommended to consider its 3D description. For this reason, and after a first study using a 3D shell mesh representing $1 / 8^{\text {th }}$ of the structure (cf. Figure 2-a, Chantron et al. 1999), the latest work was performed using a 3D solid mesh (see Figure 2-b).

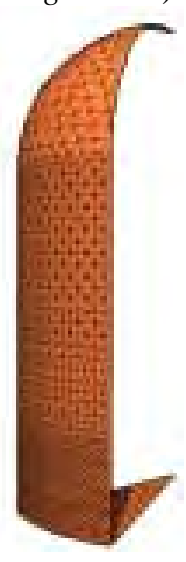

a

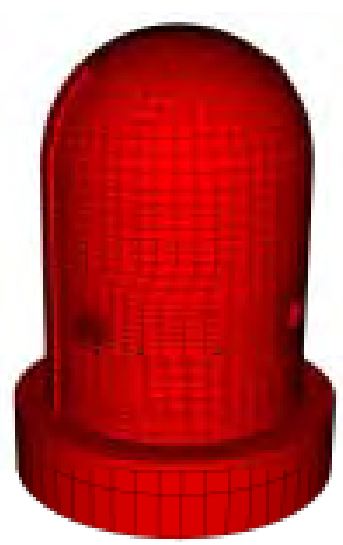

$\mathrm{b}$

Figure 2. (a) 3D shell model used for pre-test analysis, (b) 3D solid model used for post-test analysis.

\section{Meshing}

The 3D solid mesh includes most of the components of the mock-up: concretes, liner, prestressing tendons and reinforcement rebars. The concrete of basemat, cylinder wall, dome and buttresses were represented using 8 node linear solid elements (this could be improved using quadratic elements). While the behaviour of basemat was kept linear elastic, those of cylinder wall and dome were set nonlinear to exhibit cracking. The steel Liner was represented by shell elements (triangles and quadrilateral linear elements) covering the inside surface of the model, exhibiting an elastic-plastic behaviour. Reinforcement bars were modelled also using a specific shell element sustaining unidirectional strains. Two overlapped elements are used to represent the both directions of grid reinforcement. They were also set for elastic-plastic behaviour. 
Each prestressed tendon cable was individually modelled using truss elements. These are meshed separately apart from the rest of the structure. They are connected to the surrounding concrete by constraining their nodes together. Relative displacements between tendons and concrete were not permitted. Prestressing jack loads are used as input data and applied at one or both ends of each tendon, and by calculating the angular and straight distances from the ends, prestressing is evaluated along tendons using angular and wobble friction coefficients. Then tendons were all loaded simultaneously.

Considering that one of the objectives of this study was to reach the simplest modelling of the mock-up, the mesh discretisation was left as a parameter to be optimised. For this purpose a mesh generating script was developed using GIBIAN language developed by CEA (Charras et al. 1989). The script contains all geometrical data of the mock-up (dimensions, number and position of all prestressing tendons, liner and reinforcement layouts, etc). To generate a mesh, 6 parameters are needed to describe the solid par of the model, while only 2 are enough to describe prestressing tendons. These are illustrated in Figure 3.

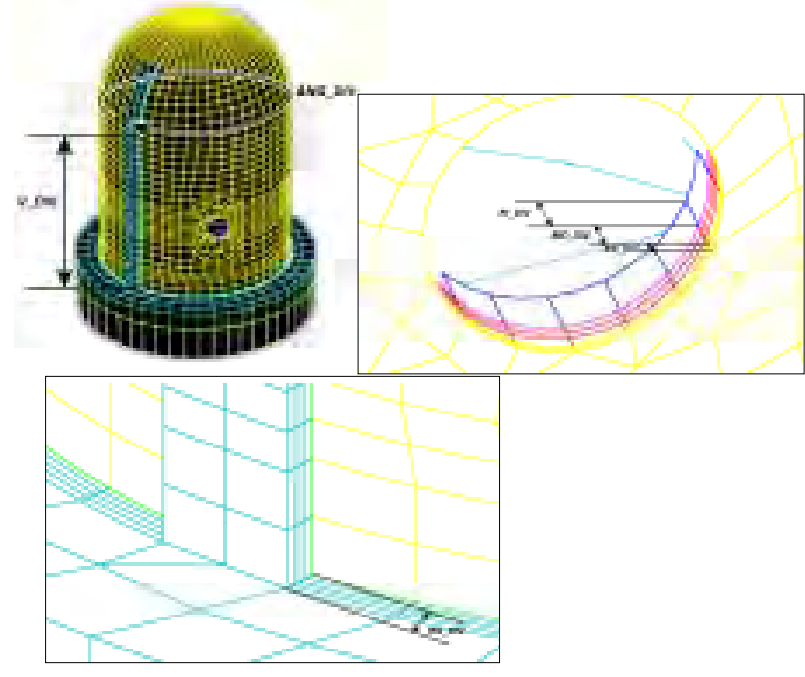

Discretisation parameters

$\begin{array}{ll}\text { ANG_DIV } & \text { Circumferential } \\ \text { RI_DIV } & \text { Concrete (Liner / Inner reinforcements) } \\ \text { RIO_DIV } & \text { Concrete (Inner / Outer, reinforcements) } \\ \text { RO_DIV } & \text { Concrete (Outer cover) } \\ \text { RN_DIV } & \text { Buttress thickness } \\ \text { V_DIV } & \text { Vertical } \\ & \\ \text { VS_IN } & \text { Vertical tendons (in deviation zones) } \\ \text { HS_IN } & \text { Horizontal tendons (in deviation zones) } \\ \text { VS_OUT } & \text { Vertical tendons (out of deviation zones) } \\ \text { HS_OUT } & \text { Horizontal tendons (out of deviation zones) }\end{array}$

Figure 3. Mesh generation script. Parameters description.

\section{Concrete constitutive law}

A part from the basemat, which had an elastic linear behaviour, the rest of the model could exhibit material non linearities. To measure the influence of the material law two models were used: Endo_Isot_Beton (Badel 2001, Badel 2005) and Mazars (Mazars 1984, Michel-Ponnelle 2005). These are both scalar models based on continuum damage mechanics.

In its "local" formulation, Mazars law describes the constitutive behaviour of concrete by introducing a scalar variable $D$ that quantifies the influence of microcracking. This results in the degradation of the elastic stiffness:

$$
\sigma_{i j}=(1-D) C_{i j k l} \varepsilon_{k l}
$$

where $\sigma_{i j}$ and $\varepsilon_{k l}$ are respectively the stress and strain components, $C_{i j k l}$ the fourth order elastic tensor and $D$ the damage variable. For the description of the damage growth, an equivalent strain is introduced from the local strain tensor:

$$
\varepsilon_{e q}=\sqrt{\left.\sum_{i=1}^{3}\left(<\varepsilon_{i}\right\rangle_{+}\right)^{2}}
$$

where $\left\langle\varepsilon_{i}\right\rangle_{+}$are the positive principal strains. The loading surface $f$ is defined by:

$$
f\left(\varepsilon_{e q}, \kappa\right)=\varepsilon_{e q}-\kappa
$$


where $\kappa$ is the history variable which takes the maximum value reached by $\varepsilon_{e q}$ during the history of loading, $\kappa=\operatorname{Max}_{t}\left(\varepsilon_{e q}, \kappa_{0}\right) . \kappa_{0}$ is a parameter of the model and represents the initial threshold from which damage grows. The evolution of damage has the following form:

$$
\begin{aligned}
& \text { if } f\left(\varepsilon_{e q}, \kappa\right)=0 \text { and } \stackrel{o}{f}\left(\varepsilon_{e q}, \kappa\right)=0 \text { then } \quad\left\{\begin{array}{l}
D=h(\kappa) \\
\kappa=\varepsilon_{e q}
\end{array} \text { where } \stackrel{o}{D} \geq 0\right. \\
& \text { otherwise }\left\{\begin{array}{l}
o \\
D=0 \\
o \\
\kappa=0
\end{array}\right.
\end{aligned}
$$

Damage evolution law $h(\kappa)$ differentiates the mechanical responses of the material in tension and in compression by introducing two scalars $D_{t}$ and $D_{c}$.

$$
\begin{aligned}
& D=\alpha_{t} D_{t}+\alpha_{c} D_{c} \\
& D_{t, c}=1-\frac{\kappa_{0}\left(1-A_{t, c}\right)}{\kappa}-\frac{A_{t, c}}{\exp \left[B_{t, c}\left(\kappa-\kappa_{0}\right)\right]} \\
& \alpha_{t, c}=\left(\sum \frac{<\varepsilon_{i}^{t, c}><\varepsilon_{i}>_{+}}{\varepsilon_{e q}^{2}}\right)^{\beta}
\end{aligned}
$$

$D_{t}$ and $D_{c}$ are tensile and compressive parts of the damage. $A_{t, c}, B_{t, c}$ are four parameters of the model. The weights $\alpha_{t}$ and $\alpha_{c}$ are computed from the strain tensor $\varepsilon$. They are defined as functions of the principal values of the strains $\varepsilon_{i j}{ }^{t}$ and $\varepsilon_{i j}{ }^{c}$ due to positive and negative stresses. In uniaxial tension, $\alpha_{t}=1, \alpha_{c}=0$. In uniaxial compression $\alpha_{t}=0, \alpha_{c}=1$. The exponent $\beta$ reduces the effect of damage on the response of the material under shear compared to tension.

In their basis Endo_Isot_Beton and Mazars are quite similar. However important numerical difficulties did not allow us to obtain interesting results for Endo_Isot_Beton. For more detail concerning its formulation the reader is invited to read (Badel 2001).

Steel (liner, rebars, tendons, opening covers) constitutive law and other characteristics

Steel behaviour is represented using a classical elastoplastic linear kinematic strain hardening model. This was applied to rebars, tendons and liner. The penetration covers were kept linear elastic.

Rebars were meshed using shell elements exhibiting uniaxially. Two overlapped layers of element were then used to describe both horizontal and vertical reinforcements. Considering the variations in rebar sections, these elements were separated into zones with different characteristics. Their values and positioning are more extensively detailed in (Ghavamian 2005, Hessheimer 2003).

\section{Loading}

The first load is the body weight, which is obtained using the gravity and the density for each component of the structure. Prestressing of the tendons is then applied gradually to reach the initial state obtained by tendon jacks. Then we gradually applied the hydraulic pressure caused by the presence of water. This is obtained by applying a surface pressure on the internal surfaces of the model (basemat, cylindrical wall, hatch covers and dome) by varying its intensity with the height. The final load was the internal pneumatic pressure, which was gradually raised from zero to the ultimate load step. This was also a surface pressure uniformly added over the entire inner surface of the model. No temperature change was considered in this study.

\section{Comparison measures}

A large amount of data was acquired during the tests. These concerned displacements, strains, forces (tendons) pressure, sound emissions, and visual observations. Among these, 55 measures were selected for the purpose of this benchmarking. Some of these comparisons are provided further in this paper. These are mostly displacement and strain evolutions vs internal pressure. Measuring points were identified with their precise 
location on the test specimen. These coordinates were then used to select the closest node of the mesh for postprocessing and comparisons. It is important to underline that discrete measures from the experiment are compared with discrete results from the FE analysis.

\section{Numerical parameters}

Parameters of each constitutive law were adjusted to exhibit responses as close as possible to material characteristics measured in site and given in Table 1 .

Concerning tendons, the input data are initial jack forces and friction coefficients. For vertical tendons a force of $424 \mathrm{kN}$ was chosen, while the horizontal one was at $304 \mathrm{kN}$. To account for friction losses, a wobble coefficient of $0.001 \mathrm{~m}^{-1}$ and an angular coefficient of $0.21 \mathrm{rad}^{-1}$ were considered. Instantaneous sitting losses were calculated considering a sit back of $5 \mathrm{~mm}$. Some of these values were then varied and adjusted during parametric studies discussed later in this paper.

Rebar cross sections affected to each different area of the FE model and their positioning are detailed in (Ghavamian 2005).

\subsection{Results and comparison with test records}

Before any nonlinear, analysis several static linear simulations were carried out to validate the FE model. Simulations using different load cases were performed, each time activating a specific part of the mesh (concrete, liner, reinforcements). Finally body weight calculations were also performed to check the mass of the model.

Nonlinear calculations were then performed activating all components of the model, with all loads. A first calculation we carried out using Endo_Isot_Beton concrete model. However persisting numerical difficulties did not allow reaching significant internal pressure. In spite several attempts using load control techniques with different stiffness matrices, we had to change the concrete model for another one. This time Mazars's law allowed us to progress and reach the failure of the structure, but still with some convergence difficulties. For a small number of loading steps we were obliged to lower the relative equilibrium of force criteria down to several percents before moving to the next step. For the rest of the analysis, a precision of $10^{-4}$ was achieved. These calculations take almost 48 hours on an Alpha processor powered computer, using one processor.

Primary results indicated concrete cracking close to buttresses which finally lead to rebar and tendon yielding. The examination of results drew our attention to the fact that as a result of sit back of cables, the prestressing in tendons was quite low close to anchorages (see Figure 4). The sit back used for the simulations was $5 \mathrm{~mm}$. Other parameters of the modelling could also be improved, however considering the great influence of tendon prestressing on the overall behaviour of the structure, and the uncertainties regarding the exact level in their tension prior to the ultimate capacity test, we decided to concentrate our improvements on modelling the prestressing.

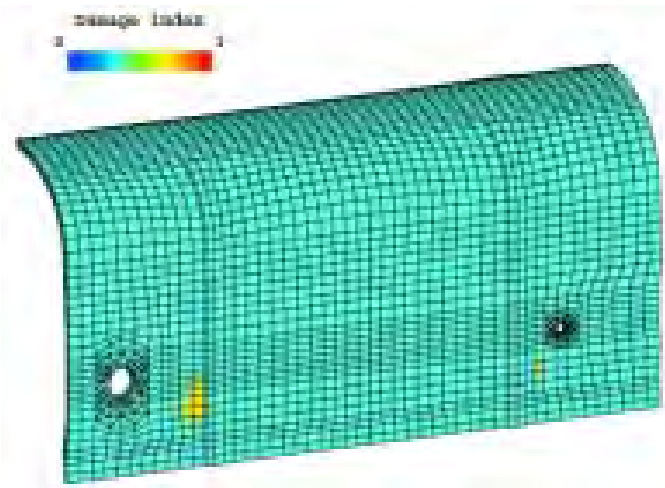

\section{Figure 4. Developed geometrical view showing the initiation of crack patterns, close to buttresses.}

A second calculation was then performed using zero sit back. This time a rupture zone initiated far away from buttresses. Although this looked promising, the location of rupture was $180^{\circ}$ opposite to the failure zone observed during the test. This time further examinations indicated an unusual deflexion mode of the structure where oscillations were observed along hoop path of the cylindrical part of the model (see Figure 5). This seamed to be related to the mesh discretisation of hoop tendons. Using the Gibiane mesh-generating script a new mesh of the cables was produced, with elements two times smaller, and this time the simulations showed no more oscillations. 

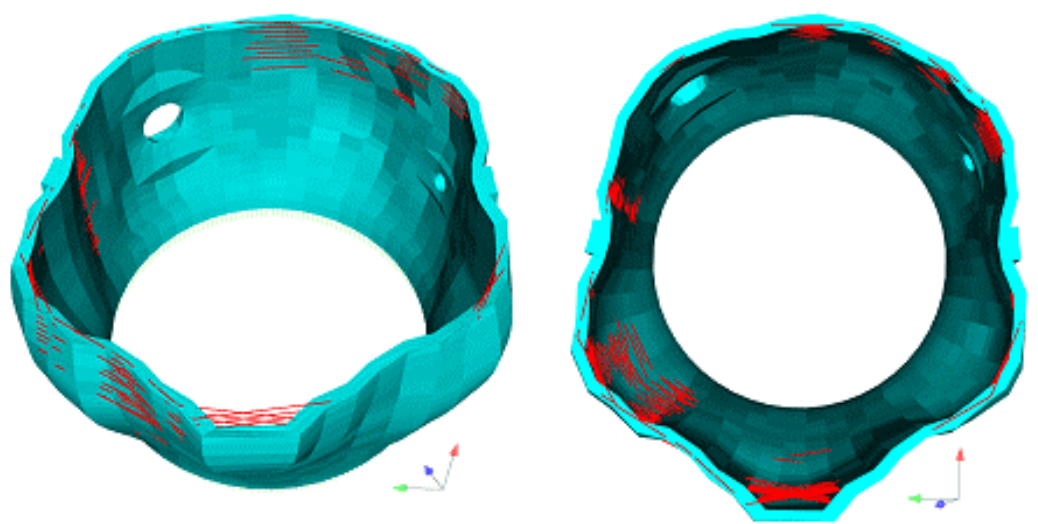

Figure 5. Cross sectional view of the model where oscillations can be seen on the deflexion mode. Red lines are tendon elements.

Although the position of the rupture did not change, by observing the level of stresses just before the initiation of the collapsed zone, it could be concluded that the profile of hoop prestressing was determinant to allow rupture occur at another location. It should be reminded that the initial profile of prestressing was achieved by resolving an analytical equation including wobble and angular coefficients of friction. While it has been proven that this method is quite accurate to determine the initial state of prestressing, one should bear in mind that after almost two years of creep and tests at lower internal pressures, as a result of tendons sliding in their ducts the prestressing tends to become more homogeneous. Something that is not included in our simulations.

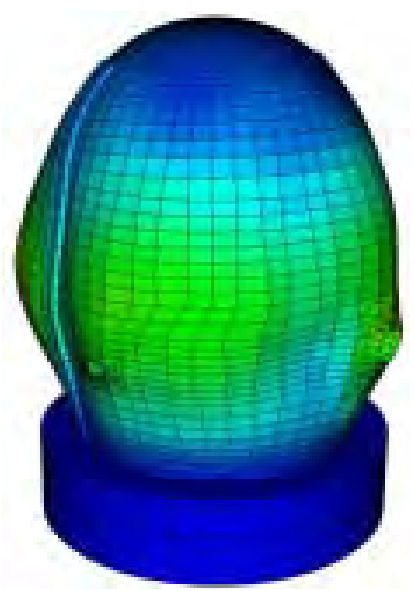

Figure 6. Deflected mesh at ultimate internal pressure. Colours indicate the level of deflection.

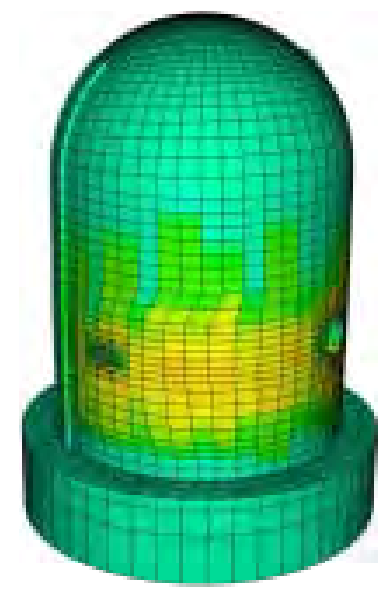

Figure 7. Mazars's concrete law damage index layout at $0.4 \mathrm{MPa}$ internal pressure (blue $=$ no damage, yellow $=$ maximum damage).

To achieve a better representation of this reality we decided to reduce the value of angular coefficient of friction from 0.21 to 0.10 before performing the last simulation. Observations from the final results made it clear that it is essential to achieve the best representation of the initial state in prestressing in order to predict that exact location of the rupture and corresponding internal pressure.

Deflected mesh and damage layout from the last simulation are shown in Figure 6 and Figure 7. Displacement results are then compared to experimental records and some of them are provided in Figure 8. 

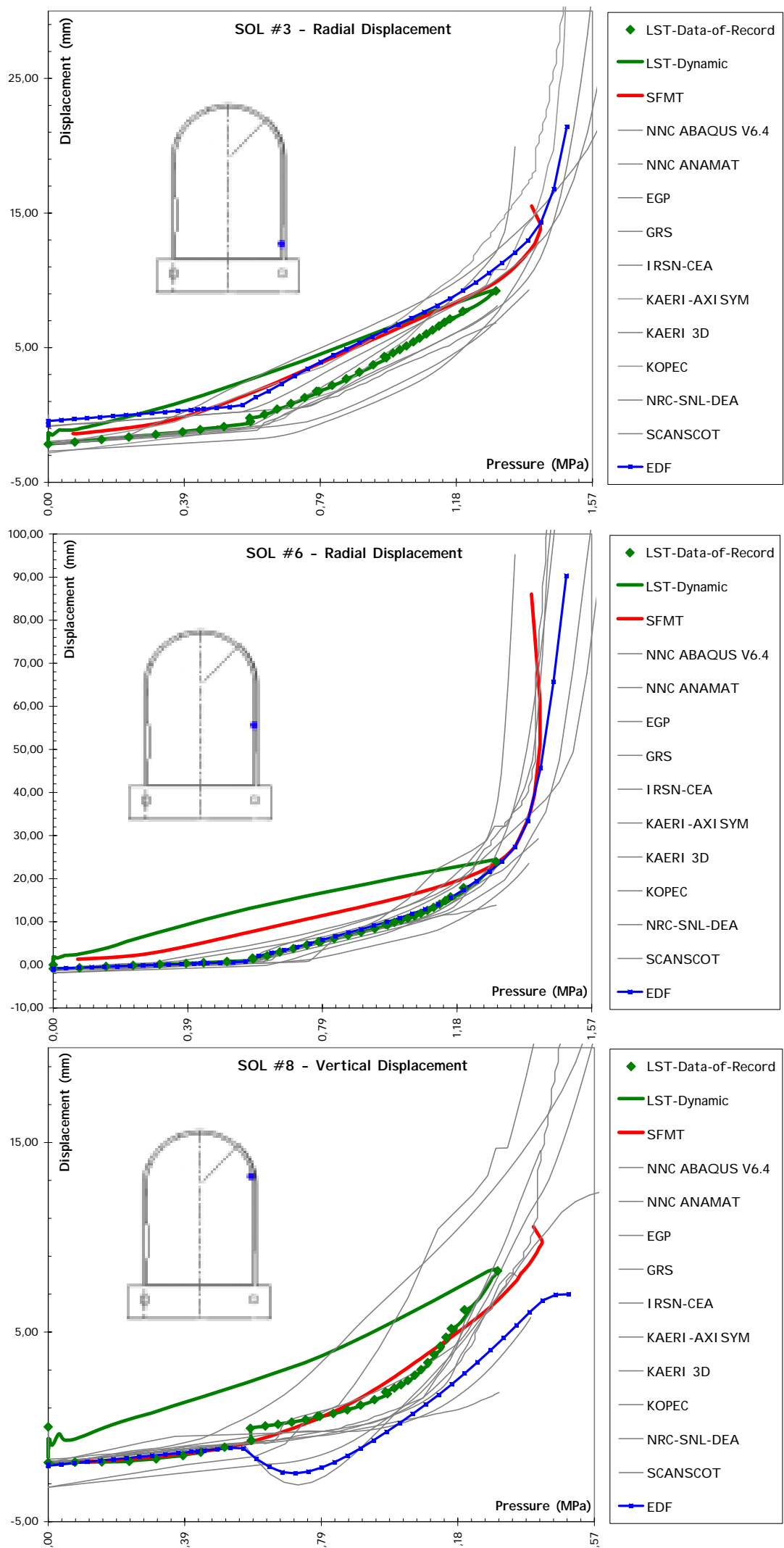

Figure 8. Radial and vertical displacements. Comparisons between simulations and test records. 


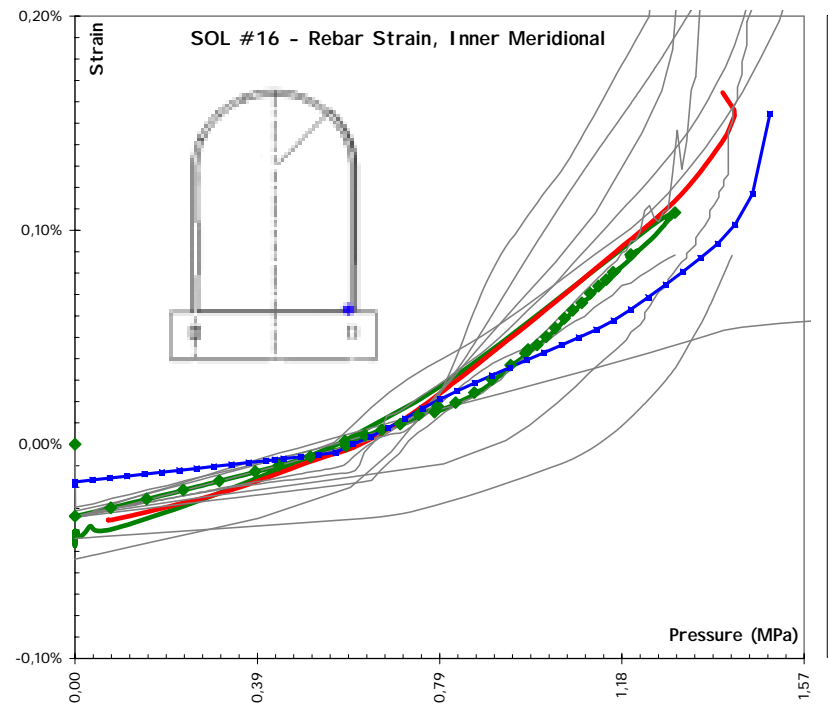

- LST.Data-of.Record

LST.Dynamic

- $S \mathcal{F M T}$

— NOC ABAQ US $V_{6.4}$

- NOC ANAMAT

E $G P$

- GRS

- IRSN.CEA

—XA ERI- AXISYM

- KAERI $3 D$

- $X P P_{E C}$

- NRC.S N NL.DEA

- SCANSCOT

$\because$ EDF

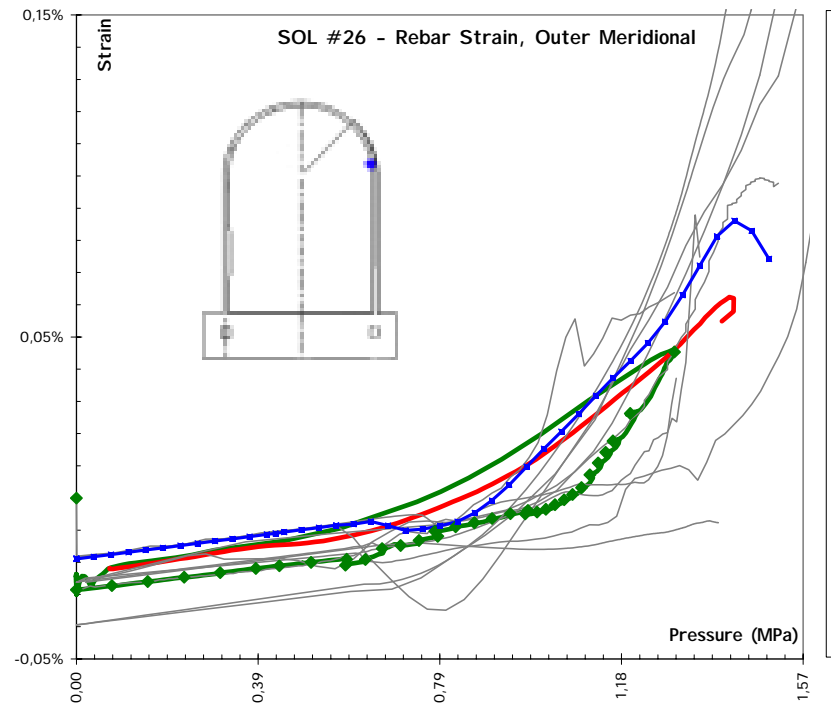

- LST.DOR

LST.Dynamic

- $S \mathcal{F M T}$

— NoxC ABAQ Us $V_{6.4}$

—oxc angMat

- $E G P$

- GRS

IRS N.CEA

- XAERI - AXIS YM

— KA ERI 3D

- $X O P E C$

- NRC.S N N.DEA

- SCANSCOT

$\longrightarrow$ EDF

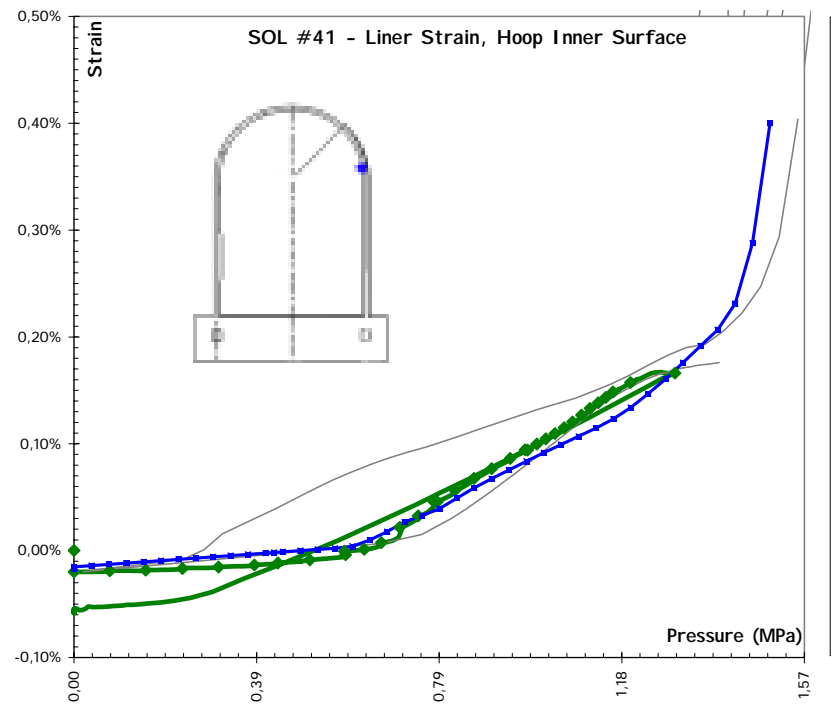

- LST.DOR

\section{—STT.Dynamic}

- NONC ABAQ US V6.4

- NOK ANAMAT

$-\mathcal{E} \mathcal{P} P$

- GRS

IRSNCCEA

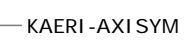

- KAERI 3 D

- KOPEC

- NRC.S NL.DEA

- SCANSCOT

$\rightarrow$ EDF

Figure 9. Radial and vertical strains comparisons between simulations and test records. 


\section{COMMENTS AND CONCLUSIONS}

In order to improve, qualify or disqualify the physical accuracy of mechanical models, it is essential to perform benchmarkings based on real experimental results. This has been our first priority in participating in ISP48. Our second objective was to investigate the influence of different parameters in simulating the behaviour of a reactor building in order reach recommendations that could lead to the best quality / cost ratio FE modelling.

Several investigations concerned the damage material constitutive law of concrete, mesh refinement, anchorage sit back and coefficients of friction in tendons. These allowed us to reach a FE model with results that compared to experimental measures can be considered promising.

At this moment these two goals are achieved and it is quite positive to reach such well agreements with a full 3D FE model. However great improvements need to be brought to both the FE model of SANDIA, and simulation platform Code_Aster ${ }^{\circledR}$.

Several difficulties in the Gibiane mesh-generating script prevent us from mesh sensitivity analysis. This was only carried out for tendons, where results were greatly improved by using more refined discretization. It appears to us that it is very important to quantify the variations in results when the refinement of the mesh changes. For which extensive computing time is also needed when dealing with very refined meshes.

The way that prestressing is modelled with Code_Aster ${ }^{\circledR}$ needs to be improved to enhance mesh compatibility when concrete and tendons are descretized separately. While this technique has the advantage of an easier FE mesh creation, strong care should be taken to maintain compatibility between solid (concrete) and bar (tendon) elements.

Convergence difficulties are always present when simulations are made using an implicit resolution technique. This was also our case. In trying to study the influence of two different damage concrete models we encountered too many numerical difficulties for one of the models, while the second one produced lesser difficulties for several load steps where we had to loosen the equilibrium criteria. Numerical difficulties and important computational cost also make if tedious to perform thorough parametrical studies, which are essential to fully understand the complexity of simulations of such structures. EDF will perform further analysis to improve its knowledge of these simulations by taking full advantage from the great amount of measurements recorded during SANDIA II tests, which are not yet exploited.

\section{REFERENCES}

Badel P., 2001, Contribution à la simulation numérique de structures en béton armé. Thèse de doctorat de l'Université Piere et Marie Curie (Paris VI)

Badel P., 2005, Loi de comportement ENDO_ISOT_BETON, Manuel de référence, Fascicule R7.01 : Modélisations pour le Génie Civil et les géomatériaux, Document : R7.01.14. www.code_aster.org, EDF

Chantron J., Bisch Ph., 1999. SANDIA II - Analyse du modèle axisymetrique. Séchaud et Metz, Villeurbanne France

Charras Th., Lautard J.J., Robeau M.F., Verpeaux P., 1989. Langage GIBIANE : Définition. Rapport DEMT/SERMA/89 . http://www-cast3m.cea.fr/cast3m/index.jsp. Commissariat à l'Energie Atomique.

Ghavamian Sh., 2005, Posttest analysis of Sandia II model with Code_Aster ${ }^{\circledR}$. MECEN poject. EDF R\&D HT$64 / 05 / 008$

Hessheimer M.F., Klamerus E.W., Rightly G.S., Lambert L.D. and Dameron R.A., 2003. Overpressurization Test of a $1: 4$-scale prestressed concrete containment vessel model. NUREG/CR-6810, SAND2003-0840P, Sandia National Laboratories, Albuquerque NM.

Michel-Ponnelle S., 2005, Modèle d'endommagement de Mazars. Manuel de Référence, Fascicule R7.01 : Modélisations pour le Génie Civil et les géomatériaux, Document R7.01.08. www.code_aster.org, EDF

Mazars J, 1984, Application de la mécanique de l'endommagement au comportement nonlinéaire et à la rupture du béton de structure. Thèse de doctorat d'état de l'Université Paris VI

Pijaudier-Cabot G., Mazars J. and Pulikowski J., 1991, Steel-concrete bond analysis with non local continuous damage, J. Structural Engineering ASCE 117, 862-882 